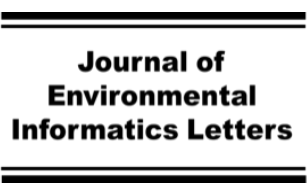

www.iseis.org/jeil

\title{
Ecological Impact Analysis of Dispersants and Dispersed Oil: An Overview
}

\author{
X. D. Ye ${ }^{1 *}$, Z. W. Zhu ${ }^{1 *}$, F. Merlin ${ }^{2 *}$, M. Yang ${ }^{1 *}$, B. Chen ${ }^{1}$, K. Lee ${ }^{3}$, and B. Y. Zhang ${ }^{1 *}$ \\ ${ }^{1}$ Faculty of Engineering and Applied Science, Memorial University, St. John's, NL A1B 3X5, Canada \\ ${ }^{2}$ Oil Spill Response Consultant, Freelance 29200, France \\ ${ }^{3}$ Fisheries and Oceans Canada, Ecosystem Science, Ottawa, ON K1A OE6, Canada
}

Received 27 March 2021; revised 25 April 2021; accepted 29 April 2021; published online 21 May 202021

\begin{abstract}
Soaring oil demand, as a result of industrial development, boosts oil exploration and production activities at sea, even into deeper and icier waters. The transportation of the oils, as well as the potential spill accidents and associated pollutions are thus increased. There is an urgent call for contingency planning with effective and eco-friendly oil spill cleanup responses. Dispersant applications can facilitate the breaking up of oil slicks into small oil droplets, allowing their rapid dispersion, dissolution, dilution and biodegradation in the water column. Dispersants have been recognized as effective oil treating agents and well adopted. Nearly 7 million liters of chemical dispersants, mostly Corexit ${ }^{\circledR}$ 9500A, were used after the Deepwater Horizon oil spill incident. However, debates over dispersants continued with major concerns about their environmental impacts and the ecological toxicity, which need to be well reviewed and tackled. Therefore, this study summarized the recent lab- and meso-scale studies and field trials on the ecological impact analysis of dispersants and the chemically dispersed oils. By providing an up-to-date review of the ecological toxicity and environmental impact assessment, this study would help to bridge the knowledge gaps in the field and facilitate future dispersant applications.
\end{abstract}

Keywords: dispersants, dispersed oil, marine oil spill, ecological impact, toxicity.

\section{Introduction}

Oil exploitation, extraction, refining and transportation activities, particularly in the marine environment, have been increasing in recent years (Li et al., 2016; Zhang et al., 2019). As a result, there has been a sharp increase in marine oil spills all over the world caused by natural seeps or accidental releases from oil wells, pipelines, drilling rigs, or transportation tankers (Liu et al., 2015; Shubbar et al., 2019; Ye et al., 2020). The spills would trigger severe physical, chemical, and biological hazards to the local marine environment and negative impacts to society and humans (Saadoun, 2015). For example, the "Deepwater Horizon" oil spill accident (DWH) in the Gulf of Mexico, one of the most serious oil spills in the history, released over 210 million gallons of crude oil into the marine environment and caused 11 deaths and 17 people injured (Xue et al., 2015; Harrison, 2020). The Sanchi oil tanker collision caused fire, explosion, and sinking with 32 deaths and a spill or burn of over 100,000 tons of petroleum products (Wan and Chen, 2018). The accidents not only led to a great financial loss (e.g., fisheries and tourism), but also damaged sensitivities zones, habitats and shorelines seriously. Effective response options

\footnotetext{
* Co-first authors: X. D. Ye, Z. W. Zhu, F. Merlin, and M. Yang.

** Corresponding author. Tel.: +1 709-864-3301.

E-mail address: bzhang@mun.ca (B. Y. Zhang).

ISSN: 2663-6859 print/2663-6867 online

(C) 2021 ISEIS All rights reserved. doi:10.3808/jeil.202100058.
}

and contingency plans are thus urgently needed after an oil spill to minimize the overall impacts (Doerffer, 2013). Dispersants are chemical or biological spill treating agents that can accelerate the formation of small droplets of oil and promote the oil disperse through the upper layer of the water column (Chen et al., 2019). The use of dispersants could reduce the impacts to the shoreline and biota on the water surface and promote biodegradation of oil (Zhu et al., 2020). Chemical dispersants have been widely adopted as marine oil spill treating agents. Nearly 7 million liters of chemical dispersants, mainly Corexit ${ }^{\circledR}$ 9500A, were applied as a response to the Deepwater Horizon incident in 2010. This is the largest known application of dispersants to treat marine oil spills (Wise and Wise, 2011).

Dispersants are a mixture of emulsifiers, wetting agents, and oxygenated solvents. For example, the Corexit ${ }^{\circledR} 9500 \mathrm{~A}$ dispersant includes surface-active agents (e.g., sorbitan fatty acid esters and their derivatives), solvents (e.g., propanediol, ethanol, and propanol), and hydrotreated light petroleum distillates. Instead of directly decrease the amount of spilled oil, dispersants help reduce the interfacial tension between oil and water. Thus, the small-size droplets, broken up from oil slicks, can be dispersed into the water column. The immediate dissolution of oil droplets into the water column could substantially increase the oil concentration to 1,000 ppm in the first minutes (Prince, 2015). Accordingly, adverse impacts on the environment would be weakened due to the increased bioavailability of dispersed oil. The use of dispersants in the field is a trade-off between reducing the risk of coastal habitats and possibly increasing environmen- 
tal losses in waters. Such a decision must consider the complex interaction of many factors, with further research on ecological toxicities and impacts of dispersants and dispersed oil. In this review, current studies and tests related to ecological toxicities using multiple scale testing systems have been summarized. This review would help to provide literature supports for further research activities in the field, and facilitate oil industries and spill response organizations to increase their dispersant application capabilities.

\section{Ecological Toxicity Assessment of Dispersants and Dispersed Oil}

The oil concentrations in the water column at the time of treatment (immediately after applying the dispersants to the oil) are typically about $10 \mathrm{ppm}$ to a few dozen ppm. Though considered as non-negligible compared with the values of acute lethal toxicity to marine organisms, these concentrations drop rapidly. The prompt dilution of a dispersed plume can be illustrated by the data from the Protecmar sea trials (1980 1986) and the Sea Empress spill (1996) (Desmarquest et al., 1983; Grote et al., 2018). In 24 hours or less, the concentration of dispersed oil drops to the lethal concentration of a few ppm or a few tenths of a ppm (Lee et al., 2013). The follow-up biodegradation (i.e., weeks to months) continuously reduces the ecological impact by lowering the oil concentration in the water column. As one of the primary factors, biodegradation eliminates the lightest fractions of the oil, which have the most acute toxicity. In the end, the remaining components of the oil, which are heaviest, least bioavailable and less toxic, are dispersed over a broad geographical area at extremely low concentrations (Passow and Ziervogel, 2016).

The ecological impact of dispersed oil at the open sea is often small or even negligible. But there is a direct impact on the areas near ecological zones where are difficult to dilute rapidly. In practice, ecologically sensitive resources (e.g., fish spawning grounds and mudflats) are mainly concentrated on or near the coast. Species' sensitivity and biodiversity in the open sea are usually lower, apart from the breeding and spawnings. It is possible at certain times of a year, specific species temporarily congregate at breeding grounds and nurseries (Word, 2013). The dilution speed of a dispersed oil plume is an essential criterion for ecological exposure to the dispersed oil. The faster it is, the lower the exposure of living resources with the dispersed oil. High dilution rates of the chemically dispersed oil droplets presuppose a turbulent environment and a large water volume (i.e., open sea conditions) (Pfetzing and Cuddeback, 1993).

Due to the different fates and behaviours of chemical and natural dispersed oils, it becomes challenging to use the net environmental benefit analysis (NEBA) to compare options with dispersants and a 'no response' option. Varied exposure routes among animals (e.g., aquatic organisms, birds, turtles, cetaceans, fur-bearing mammals) lead to the assorted risks and environmental damages (Bagby et al., 2017). In addition to the immediate consequences of oil pollution, the selection of oil spill response plans should also consider the medium/long-term im- pacts based on resource sensitivity and recovery rates. The limited research on bioavailability and toxicity of chemically and physically dispersed oil makes comparative environmental impact assessments difficult. Two toxicity evaluation approaches for dispersants have been widely used. First, the toxicity tests (using a variable loading) directly assess the differences in toxicity due to the presence of dispersants. Second, the toxicity of different oil components to various organisms can be predicted and analyzed by design-controlled modeling with a combination of experimental data.

Assessing the toxicity of oil is a complicated process. First, the toxicity depends on the testing conditions, which have not yet been standardized. For example, aquatic toxicity can be evaluated by exposure duration and concentration or static/pick/ flow-through exposure modes. Second, different criteria can be used to measure toxicity. The most commonly used one is $\mathrm{LC}_{50}$, but other criteria (e.g., $\mathrm{CL}_{0}$ and $\mathrm{CL}_{10}$, NOEC, $\mathrm{EC}_{50}$ ) could be adopted in no lethality situations. The "Species Sensitivity Distribution" (SSD), or chronic or acute HC5 (i.e., hazardous concentration for $5 \%$ of species), may be used when considering several species. Exposure conditions (i.e., concentration/duration) chosen by researchers do not always represent actual exposures (found in real incidents). Researchers use higher concentrations or longer durations to ensure that toxicological responses can be observed. In contrast, more representative test protocols for operational decisions are those for water mixing and dilution during exposure. Additionally, oil is a complex mixture of hydrocarbons with different water solubilities, forming coarse or fine dispersions (Goodarzi and Zendehboudi, 2019). The variation of the oil concentration in the water-oil solution and the amount of oil dissolved in the water may affect the toxicity of dissolved and dispersed oil, and thus result in their different contributions to the overall toxicity. Lastly, the oil composition is progressively changing due to the weathering processes. Fresh or partially weathered test oil affects oil composition and performance.

The following suggestions have been proposed to enhance the comparability and reproducibility of the toxicity data and improve their practical application to actual spill situations (National Academies of Sciences and Medicine, 2020).

- Improving the chemical characterization of the source oil (considering as many individual constituents as possible);

- Considering both dispersed and dissolved phases by analyzing unfiltered and filtered water samples or passive sampling of the dissolved concentration to account for the relative contribution of microdroplets;

- Developing/using standardized protocols aligned with operational use;

- Questioning the relevance of mixing energy levels for preparing the (water accommodated fractions) WAFs with the generation of useful data to validate toxicity models. It is preferable to identify mixing energy that can be used to prepare WAFs and CEWAFs (chemically enhanced WAFs).

In addition to the topics related to dispersant efficacy and environmental impact, safety and human health concerns related to dispersant application have appeared as a new issue (Curd, 
2011). Applying dispersants in the DWH incident reduced human exposure to volatile oil compounds and further decrease the environmental damage. This incident led to some developments in the possible impact of oil, dispersed oil and dispersant on humans. The developments include the inclusion of this objective (reduction of human exposure) in recent operational guidelines and the need for monitoring plans with specific data related to human exposure (Board et al., 2020). According to the collaborative report issued by the National Academies of Sciences and Medicine (2020), main recommendations regarding human health include developing criteria for human exposure to dispersant and dispersed/undispersed oil; integrating relevant sampling and measurements into monitoring programs to monitor these criteria; including (positive and negative) effects on safety and human health in decision-making processes; providing workers with relevant information on the potential effects of dispersants on humans and the precautions to be taken when using them; reviewing and clarifying the procedures and appropriate criteria for decisions on closing and opening fisheries. The topic of safety and human health preservation is crucial in decision-making in oil spill response, especially regarding chemical dispersion.

\section{Laboratory Ecological Toxicity Tests}

The methodology adopted for possible toxicological impact assessment depends on the purposes, namely the toxicity tests for dispersant screening, rule development for dispersant applications, or long-term consequence evaluation of using dispersants. Generally, the ecological consequences are important issues and have a significant financial impact on the process of compensation claims. Thus, the ecological assessment should be taken into account before, during and after an event. It should also be concerned to control upstream in preparation (e.g., selecting the least toxic dispersant, defining appropriate rules for using dispersants), and evaluate the environmental or economic damages in the response and after an incident. The ecological toxicity tests at a laboratory scale can control the changes of parameters and have a better understanding of causes and effects of experimental factors to toxicological impacts of oil with dispersants.

In theory, the ecological impact assessment of dispersant application (e.g., the impact of the oil plume dispersed in open water) should be considered in a medium- to long-term period with and without dispersant applications (e.g., the overall environmental impact of the aged oil drifted on the coast). However, the difference in oil weathering process at the two scenarios (i.e., fresh oil in open water and weathered oil at the coast) makes such comparison impossible. It is also challenging to cover toxicity assessments on all the species of animals and plants in the whole set of scenarios. In practice, toxicity comparsion should be made between the chemical dispersed oil plume and the untreated oil plume under the same conditions to conclude the contributions by chemical dispersion. To distingurish the toxicity/impact of the chemically dispersed oil from the ones of naturally/non-dispersed oil is of great imporatance. Otherwise, much higher ecological impact than the actual situation could be reported, distorting the conclusion and resulting in the rejection of dispersants. In addition, the toxicity data generated by limited species (usually one to a few) lacks a representativeness. Finally, an oil pollution can cause acute, delayed, lethal or sublethal toxicity due to different processes (e.g., injection, absorption, contact). The experimental methods to evaluate these effects vary and each test covers only a part of the toxicity assessment.

Acute toxicity tests are the simplest toxicity test. In principle, these tests expose living organisms with increasing doses or concentrations of target contaminants (e.g., dispersants, oils, oily emulsions). The toxicity effects are thus measured in terms of mortality rate under the increasing pollutant concentrations. In some cases, however, it may be a cessation of metabolism or function. For example, the Microtox test observes the attenuation and then the cessation of the bioluminescence function on luminescent microorganisms. The $\mathrm{EC}_{50}$ data is generated when the concentration of bioluminescence is reduced by half. Such tests generate a curve (i.e., effect $=\mathrm{f}($ concentration $)$ ) generally of a sigmoid shape. It can determine the concentration of pollutants that kills (or inhibits) $50 \%$ of exposed organisms $\left(\mathrm{LC}_{50}\right.$, or possibly $\left.\mathrm{IC}_{50}\right)$. In the context of pollution control, the objective is to minimize damage. The maximum concentration $\left(\mathrm{LC}_{0}\right)$ with no observed consequences should be sought. But this threshold is more difficult to determine than the $\mathrm{LC}_{50}$ with a larger uncertainty. Therefore, $\mathrm{LC}_{50}$ is the most commonly used reference. $\mathrm{LC}_{10}$ represents the concentration with an observed effect for only $10 \%$ of exposed organisms, which is easier to establish and can be a compromise between the goal of minimizing the impact and the need for precision (Figure 1).

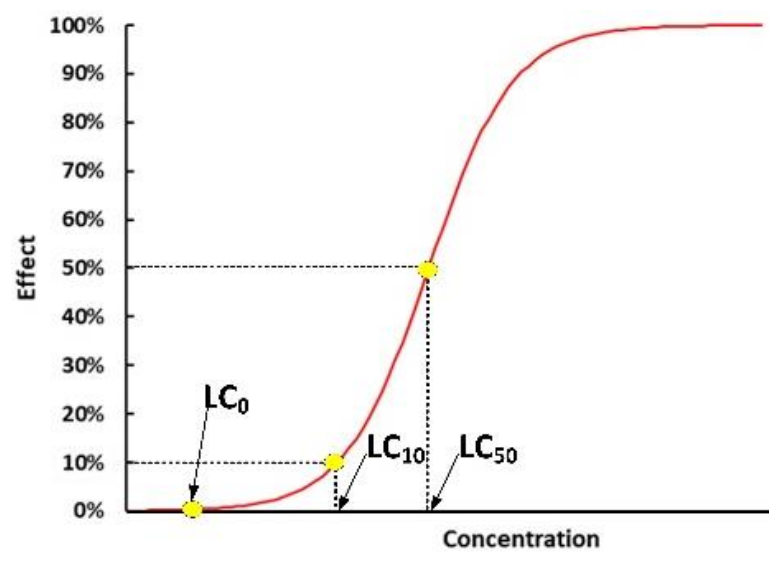

Figure 1. A typical acute toxicity curve with $\mathrm{LC}_{0}, \mathrm{LC}_{10}$, and $\mathrm{LC}_{50}$.

As part of the approval process, these acute toxicity tests are commonly used to determine the toxicity of dispersants. In some cases, the shapes of the curves may be different. This is particularly the case for bivalves which perceive as the pollutant (chemo-detection) close to their shell and defend themselves (isolating themselves from the outside). In this case, the determination of a lethal concentration is no longer possible (Figure 2). It shows that the lethality could be reached only for 

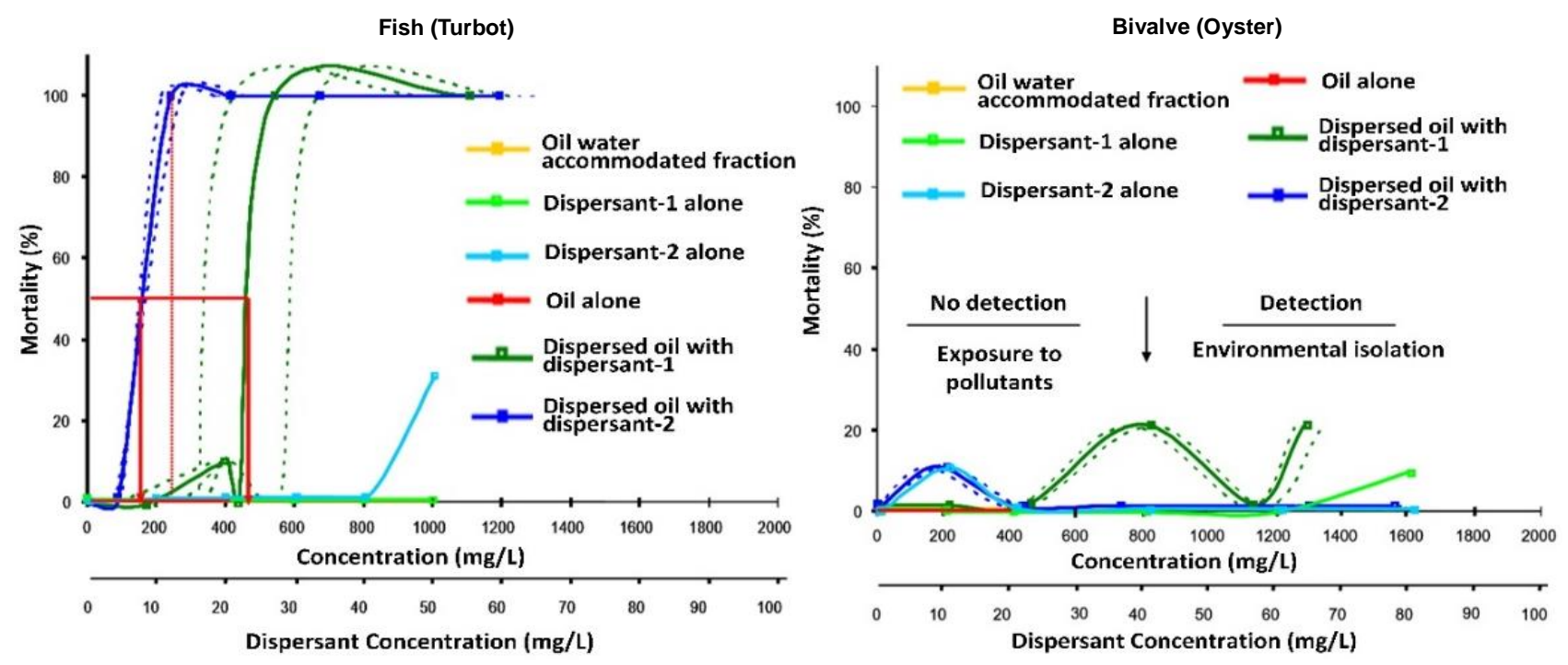

Figure 2. Acute toxicity curves on fish (left) and on bivalvesoyster (right) for different exposures (Revised based on Floch, 2012).

the dispersed oil (i.e., dark blue and green curves). For the curve of oil alone (red), exposure concentration kept too low to see any effect (the mechanical dispersion remained too unstable). Within the tested concentration range, no toxicity can be detected for the cases of dispersant alone. For bivalves, the toxicity curve is atypical with two distinct domains. Bivalves keep the shells open until the concentrations of toxicant reached to their detection limit (Floch, 2012). Accordingly, pollutants with lower concentrations (below their detection threshold) are more toxic to bivalves than the high-concentration ones as a result of their constant exposure to the contaminants with shells open.

Other issues related to these tests include the choice of test organisms, exposure conditions and the duration:

The choice of organisms. Logically, marine species should be tested, because tested organisms should be those likely to be exposed to dispersants and dispersed oils. In practice, only a few species are documented, often just one (e.g., shrimps in England and France, a planktonic organism in Norway). When the objective is to find the least toxic dispersant, the use of a single "test" species is acceptable. It can be assumed that the most toxic products must be roughly the same for any species. However, when assessing the toxicity of dispersed oil to specify where and how to use dispersants, it is necessary to investigate different common species that may have different sensitivities toward oil. A group of species including various organisms with different lifestyles (e.g., filter feeder bivalve, crustacean, pelagic and/or benthic fish) can be selected for such tests (e.g., Discobiol program) (Merlin et al., 2011). In addition, the life stage is also very important, the early stage is the most sensitive.

The purpose of the Discobiol program was to improve practical recommendations on dispersant use in coastal or estuarine areas. The program provided reliable data on the impact of chemical or mechanical effects on biological resources in these areas. It compared the toxicity or effects of exposure to the same dis- persed oil with and without chemical dispersants (chemical dispersion versus mechanical dispersion) through experiments (Dussauze et al., 2011). Different marine organisms in a coastal or estuarine ecosystem would be used, which included up to 6 species of fish, benthic and pelagic, bivalve and crustacean. The acute toxicity and sub-lethal effects were evaluated through immune, physiological and behavioral bio-indicators. According to different series of experiments, measurements and observations were carried out in different periods. Specifically, the tests included, an acute toxicity assessment with the standardised procedure (lethal effects after 24 hours exposure, followed by 24 hours of recovery time), a sub-lethal effect assessment after a severe oil exposure (48 hours) with observation immediately and 2 weeks after exposure, an impact test of oil contaminated mudflats and oil penetration on microorganisms and benthic activity in dynamic mesocosms, and tests of medium-term effects (e.g., 6 months) on fish after being exposed to oil (Dussauze et al., 2011). The study concluded that the difference of the impacts from oil residues are smaller than expected. With 2 weeks, most were disappeared or nearly disappeared. However, the abnormalities on fish eggs and embryos were observed. Despite confirmed the need for limitations of dispersants along the coast, this study belived that current restrictions are too conservative and thus proposed to ease the current recommendations for dispersant use along the coast of France (Merlin et al., 2011).

The exposure conditions. The tested organisms can be exposed in various ways, especially the test duration. Regardless of the actual site conditions, the regulatory toxicity tests take a long period, sometimes 24 hours and usually up to 96 hours. Due to the rapid dilution/dispersion of marine pollutants, the actual exposure of organisms to contaminants is short. In the case of the Sea Empress incident, the half-life of the dispersed oil concentration was around 12 hours (Kirby, 1996). The lifespan of small spills (e.g., operational spills) in the open sea is a few hours at most. Therefore, several countries have adopted much shorter exposure times (e.g., France and England). Gen- 
erally, it would be preferable to choose a short exposure time in the rage of 6 hours (one tide) to 24 hours to understand the real toxicity of a dispersed oil plume.

The exposure concentrations in toxicity tests fixed, which fail to reflect the decreasing oil concentrations at the field as a result of dilutiont. Aurand et al. (2005) demonstrated that exposure to declining concentrations of dispersant, oil or dispersed oil were less toxic than a constant exposure. Toxicity tests with constant concentrations can be performed in the dispersant screening and approval procedures. However, it is no longer the case when assessing the toxicity of a dispersed plume. Compared with the actual situation in the field, a constant concentration would lead to an overestimation of the measured toxicity (Aurand et al., 2005). To perform tests with decreasing concentrations, it is necessary to run the experiments in systems where the water is continuously diluted (e.g., a flow-through system like the one in the French test method to assess the dispersants efficiency.

Oil properties. The oil used for the toxicity tests is also important. Due to the preparation step for decision making processes and response operations, the fact that oil has been weathered (i.e., a few hours to few days) at sea before response implementation, due to oil spill response planning and preparedness, has not been condisered in toxicity test. The use of fresh crude oil in toxicity tests would overstate the exposure of hydrocarbons. For submarine pollutions (e.g., pollutions caused by the eruption of a sub-sea oil well), the oil no longer evaporates. But its aromatic compounds are still gradually dissolving. Additionally, gas that dissolves relatively quickly in water under the pressure-temperature conditions of a deep environment. The test conditions should reproduce the presence of these gas and dissolved compounds to remain realistic. However, it is very difficult to implement.

Challenges. Finally, toxicity test of immiscible mixture is much more difficult than the assessment of stable homogeneous mixtures (ideally a substance dissolved in water). Because the previous sample is heterogeneous (i.e., the oil is not or unevenly dispersed in water) and unstable (i.e., as a dispersion which tends to settle). Resurfacing process and oil slicks adherence are obstacles to toxicity tests. It is difficult to determine the oil concentrations exposed to target organisms. Toxicity tests to compare the inherent contribution of dispersants is challenging in both cases of oils with and without dispersants.

In the UK, the toxicity tests for oil with and without dispersants (as part of their dispersant approval process) adopted a very short exposure time (i.e., only 100 minutes) with an extremely high agitation to keep the oil in suspension status (Figure 3) (EMSA, 2016). Such a high turbulence level in the test tank forces the tested animals to swim much harder than in natural environment, which increases the oxygen demand and may create some bias in the test results.

A $300 \mathrm{~L}$ tank with specific arrangements was used in the Discobiol program for dispersing oil chemically and mechanically within 48 hours. Figure 4 indicates that a small pump continuously collects oil from the surface and sprays it back to the bottom of the tank. That minimizes oil water separation and/or keep oil in the water column. Even with this equipment, a gradual decrease of oil concentration in the water column was observed due to the oil trapped, stuck on tank walls or floating at the water surface. The oil concentrations in the water columns may vary in tests with/without dispersants, which consequently affect the actual exposure of tested organisms (Merlin et al., 2011). However, the experimental model can be understood as a simplified representation of an environment exposed to chemically or mechanically dispersed oil (e.g., under wave agitation). The oil in such an environment is not necessary to have the same behavior according to the presence of dispersants.

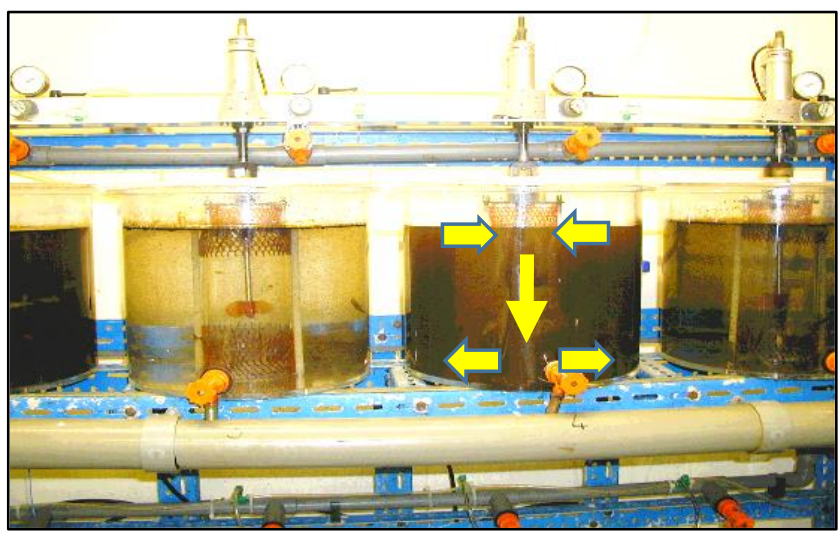

Note: Yellow arrows: a propeller is installed in the center of the cylinder tank to circulate the fluids.

Figure 3. View of the toxicity test performed in UK to compare the oil toxicity with and without dispersant (EMSA, 2016).

The protocols using the soluble fraction of the oil (mainly water-soluble oil compounds) have been developed to avoid the bias brought by a heterogeneous environment. A homogeneous aqueous solution can be obtained by keeping in close contact water and oil for a certain period (e.g., for $18 \sim 24$ hours) followed by a few hours of rest (e.g., 3 hours). Then, the polluted water only contains oil compounds that has a certain solubility in the water. This is the water accommodated fractions (WAF). When the dispersant is added, the WAF also contains the stable part of the oil dispersion and is then called the chemically enhanced water accommodated (CEWA). Working on WAF and CEWAF is much easier than working with unstable heterogeneous mixture of oil and dispersants. The mechanisms of WAF and CEWAF are potentially different as the former is based solely on the solubility of petroleum compounds and the latter brings in bulk oil droplets. However, it may be possible to object that, in the preparation of WAF and CEWAF, the settling process could result in the loss of the poorly dispersed fraction as observed in real conditions if the agitation at the sea surface is not sufficient to maintain a certain level of mechanical dispersion.

The presence of free oil droplets can have important consequences. For example, in the tests using crude oil without any particular preparation (i.e., decantation or filtration), gills fouled by pure oil on fish was observed and crustaceans affecting their 


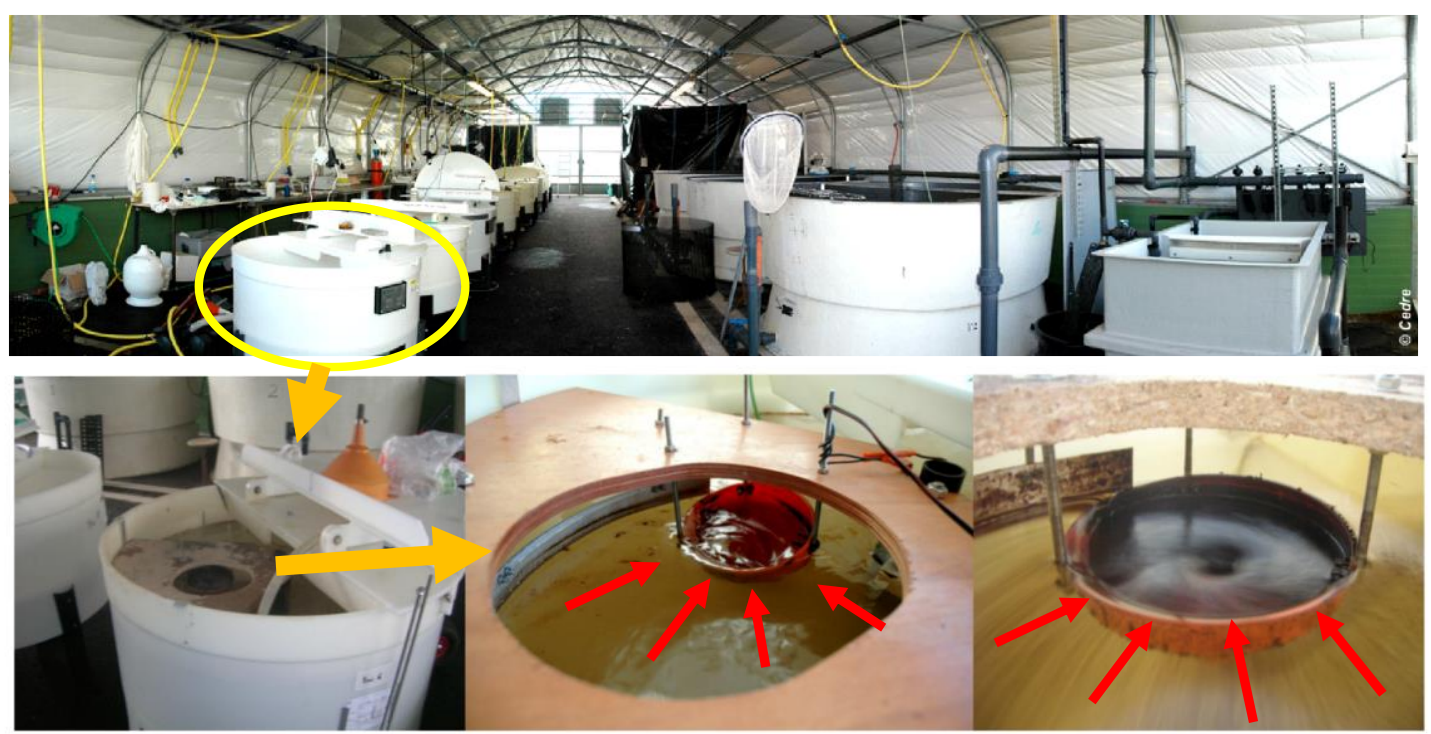

Note: Top, Cedre's facilities for impact assessment tests with 12 tanks on the left side. Bottom left, a testing tank with oil re-circulating devices. Bottom-middle, a re-circulating device with a funnel (red) connected to a small pump at the bottom of the tank to concentrate the resurfacing oil during a test with dispersants. Bottom right, the arrangement to collect surface oil during a test without dispersants.

Figure 4. Experimental arrangements used for the Discobiol program (Merlin et al., 2011).

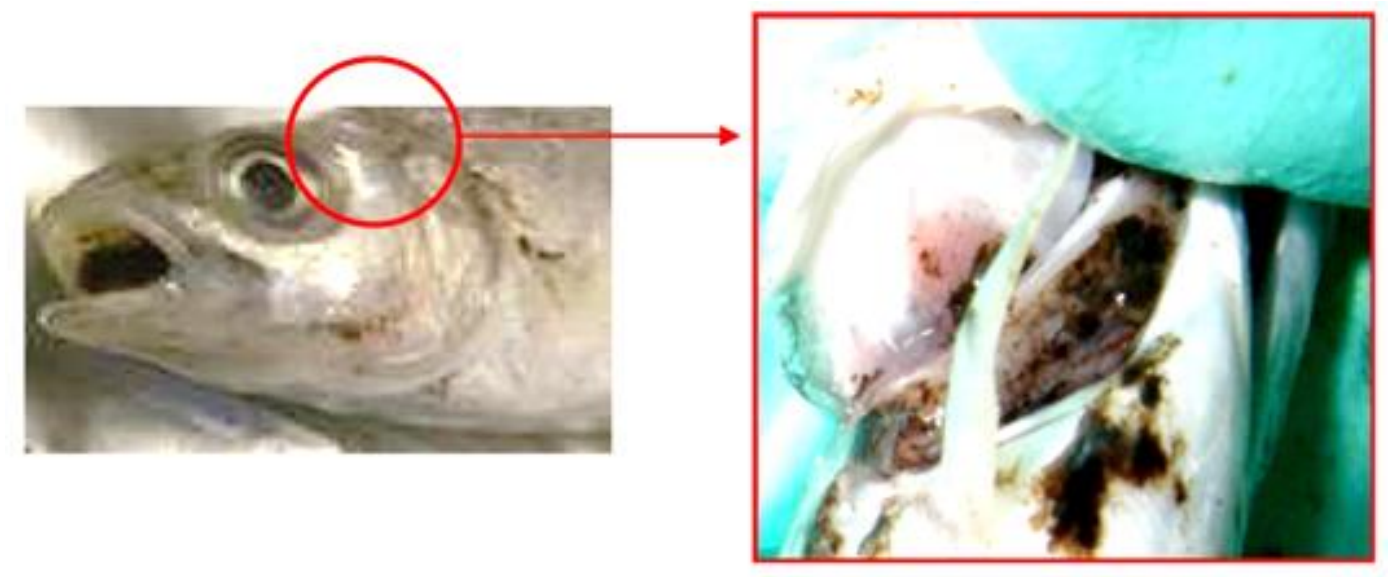

Figure 5. Observations of oil deposits at opercular and gill levels during the Discobiol program (Merlin et al., 2011).

respiration due to the presence of oil droplets in the environment (Figure 5) (Merlin et al., 2011). The experimental tests by the WAF and CEWAF fractions does not reproduce the effects of direct contacts with oil and/or smothering occurred in a turbulent natural environment (with mechanical dispersion). In such circumstances, the tests minimize the effects associated with the presence of oil alone (without dispersants). On the other hand, it reproduces the conditions that slightly agitate the environment, but most importantly, it provides higher operability and would lead to more reproducible results.

Lastly, toxicity measurements with volatile pollutants are still challenging due to the continuous evaporation of pollutants. The impact is more obvious when the medium must be aerated (by bubbling) to allow an aerobic environment. The bubbling air brings the volatile pollutants from the water into the atmos- phere. In this case, continuous recharge of pollutants into water to maintain a sufficient exposure of living organisms to pollutants is necessary. Cedre used experimental installations that the water was circulated in a tank with animals for exposure to enrich the water by contact with the pollutants (Floch, 2002).

Another important point is the relevance of the indicators chosen to assess impacts. When the test is about the lethal concentration or the appearance of malformation on the embryo, the effect is clear and especially irreversible. But reversible results could be generated for many other biological or physicological indicators (e.g., cytochrome 450, cortisol, and catalase). The indicators can have increased or decreased changes because of pollution exposures of tested organisms and then gradually return to normal when exposures cease. In such cases, these indicators reflect the exposure of tested organism with pollutants, 


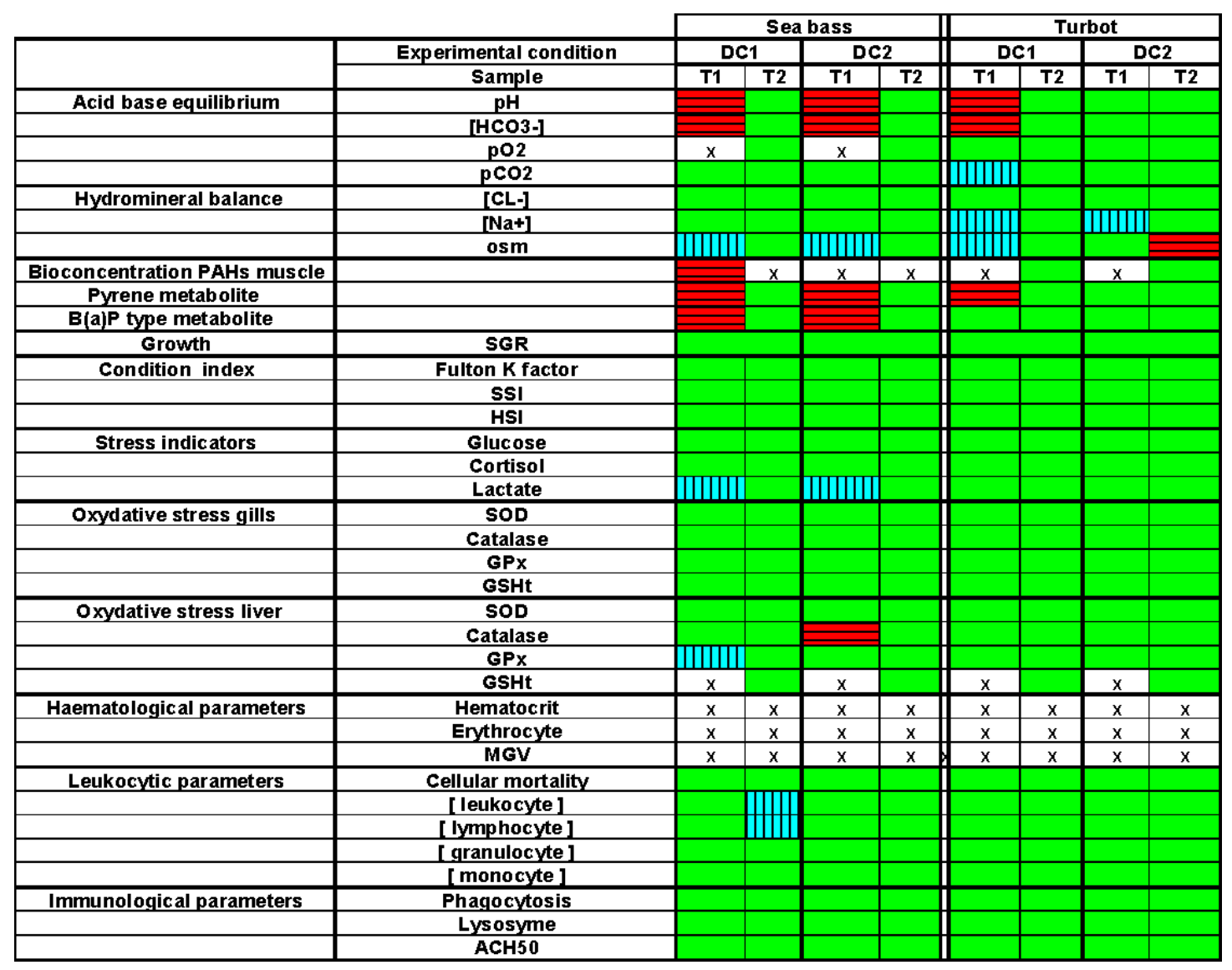

Note: The color of the boxes indicates if the indicator for chemical dispersion is lower (Blue), equal (Green), higher (Red) than the one for the mechanical dispersion (Cedre, 2011).

Figure 6. The comparison of chemical dispersion with 2 dispersants (DC1, DC2) with mechanical dispersion on fishes (sea bass and turbot) at the end of the 48 hours exposure (T1) and at the end of 2 weeks recovery time (T2).

but they do not not necessarily have a real impact. Figure 6 shows that, after two weeks of recovery from a high exposure to oil (between 30 and $70 \mathrm{ppm}$ for 48 hours), almost all indicators showed no difference between oil alone and chemically dispersed oil. Most boxes are green except for the 2 leucocytic parameters and bioconcentration PAHs muscle.

From an operational viewpoint, it is important to determine the real impact when the indicators exhibit reversible results in a short to medium term. Similarly, during the Discobiol study, the "challenge tests" were carried out on fish to measure their performance before and after exposure to oil with and without dispersant, which were to measure the time that fish performances in the testing period (e.g., to swim in an increasingly powerful tide, to endure an increasingly severe anoxia, or to withstand in an increasing high temperature) began to show signs of weakness. Even several months after the end of exposures, the mobility of fish exposed to chemically dispersed oil were slightly less active (e.g., swim a little slower) than those exposed to oil alone. The slight drop in performance could damage their competitiveness in the natural environment. But can we say that there is an impact? What is actually assessed? Is it a transient change with little effect, or a permanent change with real consequences? There are many questions about the real meaning/relevance of what is measured or observed in the toxicity tests.

\section{Mesoscale Ecotoxicity Tests}

Similar to the efficiency test of dispersants in wave tanks, mesoscale tests aim to evaluate the toxicological impacts of dispersants under a more realistic environment. The mesocosm tests can provide an intermediate spatiotemporal scale, control, and replication. They can assess ecological meaningful endpoints and assess interactive effects with multiple factors. Such tests can be achieved by simulating the exposure to a dispersed plume drifting in wave tanks, which provide the possibility to combine physico-chemical toxicity assessments in same experiments. Mesoscale tests can recreate the natural environment in mesocosms. The increased complicity also brings high variability and limited transferability. Such mesocosms should include several species with a certain degree of inter-relation representing an ecosystem. They should also be open with a renewal of the water (e.g., a flow-through arrangement), which can be done easily for small organisms, but it became more challenging for 

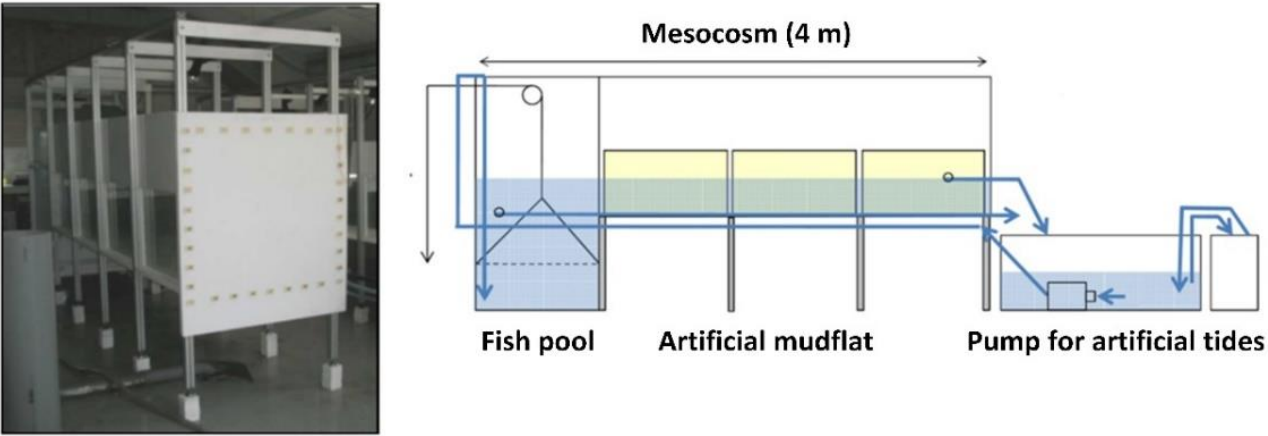

Figure 7. Photo and diagram of the mesocosm for organisms' exposure to polluted mud (Cedre, 2011).
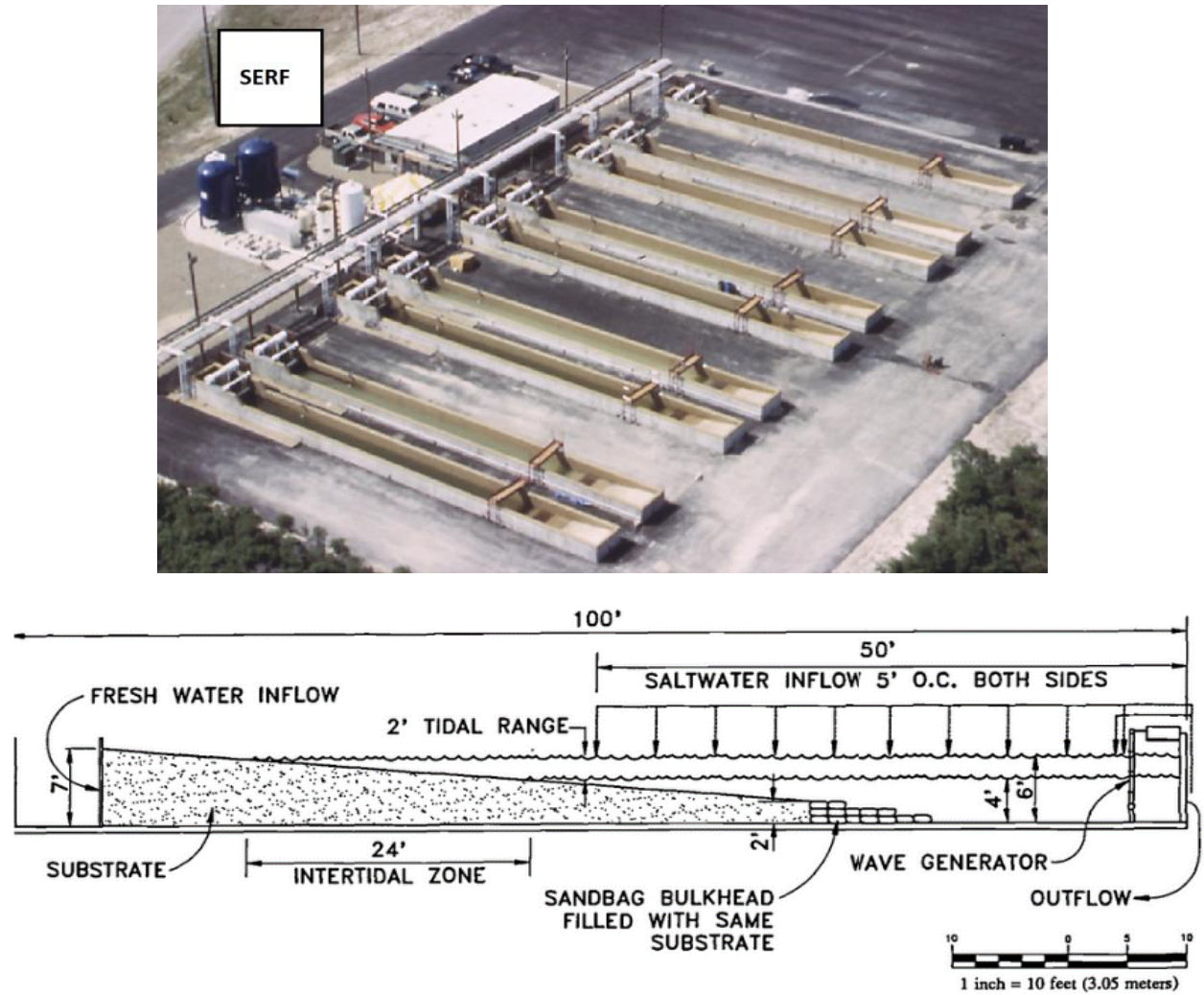

Note: Top, the laboratory and the upright tanks for the oily water treatment. Down, a wave tank designed to simulate intertidal /nearshore habitats.

Figure 8. The photo and diagram of the SERF facility (Page et al., 2001).

larger organisms. The mesoscale systems are simplified copies of the real world. For example, the mudflat mesocosms were set up in the Discobiol program (Figure 7) using fish (i.e., seabass and a grazing fish and mullet), bivalves (i.e., oyster, mussel, and scrobicularia), shellfish (i.e., hydrobia), and polychaetes, meiofauna, and mudflat microfauna as representative organisms. The mud was artificially pre-polluted with mechanically or chemically dispersed oil. Then, the fate of the mud, the behavior and the health of the animals were monitored. Tidal movements were recreated artificially during the study. This was a relatively simple mesocosm to show that oil could have a detrimental consequence, limited to the mudflat eco-compartment.
However, no significant difference was observed between two testing conditions (i.e., oil with and without dispersant) except for the microfauna which was more sensitive to dispersed oil.

To mimic a complex real environment, model physical, chemical, and biological attributes especially those of the shoreline and nearshore subtidal environments in an experiment is challenging. Maintaining the natural equilibrium can be very tricky and required rather large facilities, especially when a large number of different species are interacting and when the size of the living organism is large. Therefore, small scale laboratory studies are inherently limited in their ability to integrate all environmental variables. 
A large testing facility has been built in Texas (US) in Corpus Christi: the SERF (Shoreline Environmental Research Facility). SERF is a facility designed to accommodate variations in coastal and nearshore conditions for oil spill simulations in a tidal environment, especially a sand beach environment. It has been used to study the nearshore dispersion of oil spills (Kitchen et al., 1997). This mesoscale facility includes nine large wave tanks with a size of $33.5 \mathrm{~m}$ (length) by $2.1 \mathrm{~m}$ (width) by $2.4 \mathrm{~m}$ (height) (Figure 8). Each tank is equipped with a computer-controlled wave board that can produce variable wave patterns and feedback circuits to automatically control the tidal range and cycles (Page et al., 2001). Each of these wave tanks isy filled with $2 \mathrm{~m}$ height water, and on one end, to re-create a beach with sand (representing up to $30 \%$ of the volume of the tank). Although this facility was built specifically to study nearshore dispersion, the shoreline is optional and can be replaced with artificial wave-absorbing beaches. Water can flow through this tank at various rates for dilution. The nine identical tanks open the possibility to run experimentations with QA/QC (e.g., 3 tanks for oil alone, 3 tanks for oil and dispersants, 2 tanks without oil as control).

Despite the above-mentioned advantages, this facility has drawbacks and defects. As an outdoor facility located in South US, the temperature control during experiment is difficult. It would be particularly challenging for the simulation of temperate/cold climates, despite the addition of an equipment to modify the climatic conditions in the testing tanks. The narrowness of the tanks is another disadvantage that may create wall effects (e.g., emulsified oil sticking to the walls). Moreover, the large volume of sand (the beach) may unevenly trap a very significant part of the oil introduced in the test tank, reducing the possibility of completing a precise mass balance of the oil at the end of the tests. It was found that the beach could trap up to $49 \%$ of the oil (Fingas, 2005). Also, sand beach is a relatively simple environment when diversity and interaction between species need to be factored in.

As mentioned, recreating the complex biodiversity in a mesocosm is highly challenging. To address this problem, a large testing facility named the "pilot rivers" was developed to study the inland chronical oil pollutions. The "pilot rivers" is the mesocosms operated by TOTAL oil company in France, which have 16 identical parallel canals with a size of $40 \mathrm{~m}$ (length) by $0.5 \mathrm{~m}$ (width) by $0.50 \mathrm{~m}$ (depth) built branched on a natural river. It is used to study the effects of contaminant on freshwater environment. With the 16 canals, experiments can be planned with many replications to comply statistical requirements. Before each experiment, a part of the natural river stream flows through the "pilot rivers" to let the natural living organisms to colonize the mesocosms. The contaminant is injected in the mesocosms only at the end of this re-colonization period. Each experiment begins with a long period of time for biorecolonization by the natural environment. Figure 9 indicates that water from the studied river site was introduced into the pilot river. The "pilot river" is gradually colonized and "nursed" by plants and animals collected from a special wild area. However, such operation increases the experiment duration and therefore boosts the operational costs (Lagadec, 2009).

\section{Field Ecological Toxicity Tests}

Ecological toxicity tests have also been conduct in the natural environment. That is the warrantee of a perfectly realistic environment with all diversities. The tests can achieve a direct connection to endpoints of concerns with a large spatiotemporal scale. All possible coastal environments can be studied, even the most complex ones. On the other hand, conducting experiments in a natural environment requires permits, to make sure the testing is conducted in a strictly controlled manner to prevent the oil from spreading or diffusing outside the test area. The implementations of certain precautions need to be involved, such as taking containment measures around the test area, which may be difficult if the selected environment is agitated by water flow, waves, or currents. It must ensure that such containment does not adversely affect the living and exposure conditions of organisms and tests accordingly. Finally, the duration of this type of experiments can be long (e.g., months or even years), especially when seeking medium- and long-term effects. The protections against chronic impacts should also be considered. At last, this type of test involves finding several test areas according to the number of testing conditions studied (e.g., oil alone, oil and dispersants and the controls). The test sites should be as identical as possible but also far enough apart not to interfere with each other. Field trials have been widely used to study the effects of bioremediation treatments on relatively simple coastal facies (e.g., sandy, or muddy sandy) (Mearns et al., 1997; Lee et al., 2000; Garcia-Blanco et al., 2001). The test areas could be relatively small (e.g., a few meters) to investigate the performance of microorganism in the field, whereas "wall of absorbent" was intalled at the edge of the test areas to trap the free oil and avoid collateral damage.

A large field test $(30 \mathrm{~m} \times 30 \mathrm{~m})$, called TROPICS (Tropical Oil Pollution Investigations in Coastal Systems), was carried out in 1984 in tropical Caribbean environments on fragile and sensitive habitats that contains mangroves, sea grass and coral. TROPICS was carried out to examine the Net Environmental Benefit Analysis (NEBA) for the use or non-use of dispersants in nearshore tropical ecosystems (Figure 10) (DeMicco et al., 2011). As the mangrove environment is rather calm, the containment of the oil on the test areas could be recovered by using floating booms. The test areas have been monitored over decades ( 32 years) since the beginning of the experiment, which led to very solid conclusions on the impacts upon dispersant application, particularly on the duration of natural restoration of the biotopes (Baca et al., 2014). This type of knowledge is particularly useful to operators because it allows experts to predict the consequences of the different possible control options. As an example of the conclusion issued from such experiments, TROPICS recommended the use of dispersants to decrease the quantities of oil trapped in the sediment in the long term and reduce the environmental impact on mangroves despite the damage observed on the sea grass and the coral. They reported that the survival of the biological community was which could then support the survival of species. And the most vulnerable biomes must be prioritized when choosing a response plan. This experiment gives the operator confidence in the use of dispersants under these tropical conditions (Baca et al., 2005). 


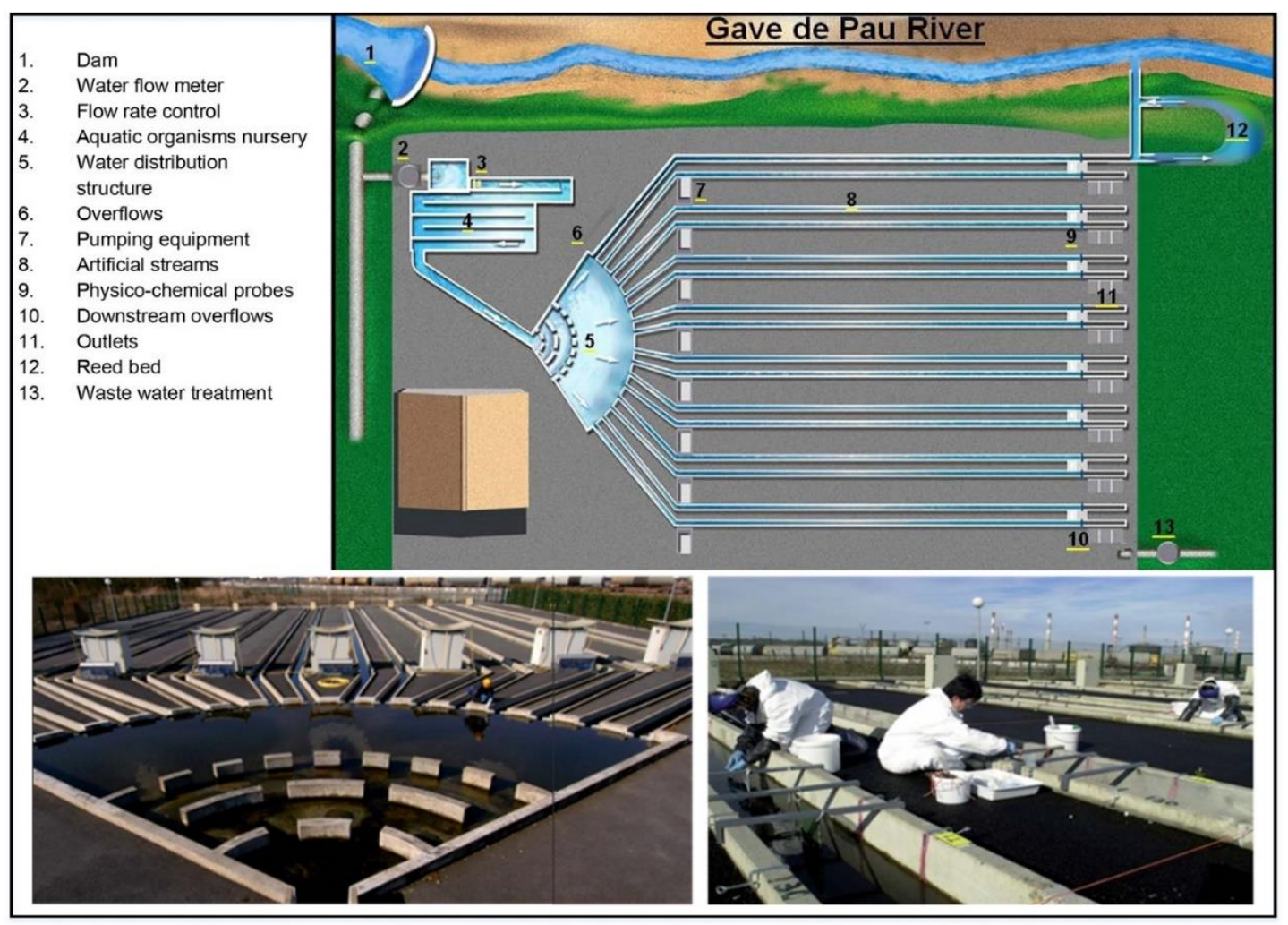

Note: The "Pilot rivers" is built branched on the natural river "Gave de Pau" (Site 1). A nursery of aquatic animals (Site 4) is set upstream the pilot rivers (Site 7) for the biological recolonization (Coffinet et al., 2008; Cailleaud et al., 2019).

Figure 9. Diagram of the "pilot rivers" system.

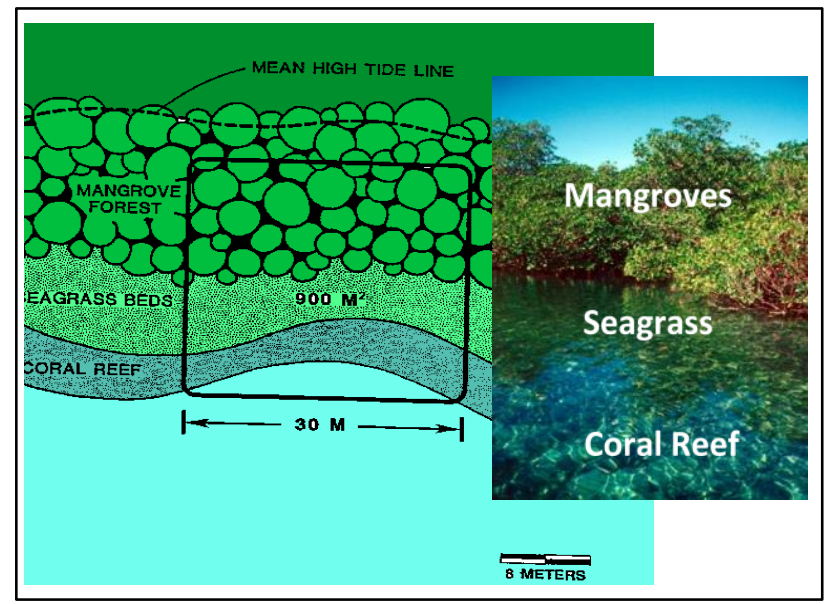

Figure 10. TROPICS experiment: test zone situation with its stepped biotopes: mangroves, seagrass, and coral reef (Ballou et al., 1989).

As an alternative to full-scale tests, an enclosure environment could be set in open water with living organisms exposed to the oils. One or a few species could be studied in situ without diffusion/dispersion of the pollutant with external environments. A field experiment was also conducted in the Arctic (Svalbard) in mesoscale few years ago as part of a study program devoted to the fate, behavior and impact of oil treated with different response options (i.e., oil alone, chemical dispersion and, in situ burning) (JIP, 2017). The mesocosms was set in the ice to study the fate and behavior of oil with and without dispersant during the winter period. During the winter period (5 months), 8 cylindrical mesocosms (1.6 m diameter and $3 \mathrm{~m}$ height) with opens on both ends were set in the ice of a fiord (Figure 11). These mesocosms designed by Cedre, took up the concept of the floating cells as an open mesocosms connected to the atmosphere and water column. They were used to monitor the oils trapped in the mesocosms, and assess their migration in the ice, composition changes, biodegradation and the impact on the microbial community (Camus and Smit, 2019). The chemical composition of the oil, total bacterial populations and oil degrading microorganisms, microbial activity and biodegradation activity, zooplankton - survival, feeding and reproduction (under ice), and ice algae primary production were evaluated. However, the oil toxicity on larger organisms (e.g., polar cod) was not the target of this study. Nevertheless, this research program demonstrated the feasibility to deploy mesocosms in Artic challenging environment to conduct environmental field assays.

\section{Modeling of Dispersants and Dispersed Oil}

Modeling works provide an efficient way with the integration of experimental works for a better understanding of 
testing results, predictions and system control or optimization. The assessments of acute toxicity of oil have generally rely on existing toxicological data of a few standard test species. But this limits the ability to estimate the impacts of spilled oil on aquatic communities. Modeling can develop the methods and algorithms by the approaches of statistics, simulation, and optimization to expand the values of experiments and compensate the shortages of experiments to fully analyze and evaluate the impacts and toxicities. The USEtox was a scientific consensus model developed for comprehensive characterization and comparison of ecotoxicological impacts (Rosenbaum et al., 2008). Fahd et al. (2019) used Bayesian belief network to model individual fish toxicity and estimate the probability of exposure concentration to cause cytotoxicity. Regarding the toxicity analysis model of dispersant and dispersed oil, Bejarano and Barron (2014) developed interspecies correlation estimation (ICE) models for petroleum and dispersant products. The models can predict toxicity values to a broader range of species and better understand taxonomic differences in species sensitivity. McCay and Graham (2014) evaluated the net environmental benefits of dispersant use with quantification trade-offs by the RPS ASA's Spill Impact Model Application Package (SIMAP). The study considered the inputs of oil type, oil volume, environmental conditions, dispersant uses, weathering processes, and toxicity to aquatic biota. Bejarano (2019) developed and refined the ICE models with the updated aquatic toxicity data on current-use dispersant. The study helped fill species diversity gaps in toxicity data and discussed the concerns of species sensitivities in hazard assessments and applications of dispersants. Liu and Callies (2020) addressed a Bayesian network for marine oil responses in the German Bight with the use of chemical dispersants. The approach considered the key criteria related to drift behavior, dispersion efficacy and ecological impacts.

The information collected from toxicity tests of chemically and physically dispersed oils is applied to establish databases. A centralized toxicity database, DTox, sponsored by Coastal Response Research Center in the US (CRRC), was developed for dispersants, oils, and dispersed oils to allow a thorough assessment of hazard concentrations (Bejarano, 2014). The metaanalysis of laboratory-based aquatic toxicity data with whole organisms better understands the effects of oils and dispersants. For example, Chemical Aquatic Fate and Effects (CAFÉ) is used to estimate the fate and effects of thousands of chemicals, oils and dispersants (NOAA, 2015; Bejarano et al., 2016; Renegar et al., 2017). This analysis includes the Natural Damage Risk Assessment (NDRA) data collected from the DWH oil spill (Bejarano, 2018). Such meta-analysis database lets users filter information on specific oils and dispersants to give decisionmakers rapid access to past research. However, it is still difficult to compare toxicity data sets, especially due to the lack of standardization between test methods.

The toxicity modeling predictions are essential for the evaluation of response options. The oil concentration parameter usually used for toxicity analysis is TPHs (total petroleum hydrocarbons). It assumes that each oil component (or each aromatic component) is equally toxic and that the arithmetic sum of the concentrations -mg component/L- or TPAHs (total poly- cyclic aromatic hydrocarbons as the arithmetic sum of only the aromatic hydrocarbons) is the proper parameter or dose metric for the toxicity predictions of the mixture. However, this is not a valid assumption since mixed oil's toxicity varies by up to four orders of magnitude (Fan et al., 2020).

A better way for toxicity predictions of a mixture of soluble oil components is to consider the contribution of each component based on the intrinsic toxicity of the component (i.e. $\mathrm{LC}_{50}$ ) and its concentration in the mixture using the "toxic unit" concept (TU) (Hermens, 1989). The toxicity unit of a mixture (TUT) is defined as the sum of the individual component contributions (i.e., the toxic unit concentrations of each oil component) (Renegar et al., 2017). The use of TUs assumes that there is no interaction/synergy/antagonism between the considered compounds, and the contribution of dispersed compounds is negligible compared to the dissolved compounds when the oil concentration is below $100 \mathrm{mg} / \mathrm{L}$ (National Academies of Sciences and Medicine, 2020). Several models (e.g., OilToxEX, Petrotox) are designed based on the TU concept to evaluate the toxicity on aquatic organisms (French-McCay, 2002; Redman et al., 2012b). The Petrotox model has been developed to predict the concentration of dissolved oil and the composition of the remaining oil phase that is expected to be present for known oil compositions and concentrations in the WAF. The concentration of microdroplets is considered to reproduce the measured concentration (Redman et al., 2012a). The predicted values from Petrotox have been compared with experimental toxicity data ( $\mathrm{LC}_{50}$ concentration) of oil samples obtained from various loading tests (Redman et al., 2017). TPAH and TPH concentrations are the metrics usually used to measure oil concentrations in toxicity tests (Redman and Parkerton, 2015). However, the results of TPHs and TPAHs may diverge from TUs-based models. Notably, if a significant difference occurs between TPAHs and TUs when TPAHs reach $100 \mathrm{mg} / \mathrm{L}$ and above, then the use of TPAHs stops to be valid. The sample oil should be fully concentrated and redistributed to calibrate/verify the models with toxicity tests. For this purpose, the use of passive sampler solid phase micro-extraction (SPME) is encouraged to provide some standardization to the toxicity testing procedure. The models are calibrated and/or validated by comparing results from other models (inter-calibration), results from laboratory toxicity tests or observations/measurements from spills. (Clark et al., 2001; Aurand and Coelho, 2005; Bejarano, 2018).

\section{Conclusion Remarks}

Dispersants have the potential to be an effective response option for marine oil spills. Current studies provide improved approaches for the analysis of ecological impacts of dispersants and dispersed oil. The lab-/meso-/field-scale ecological toxicity tests are valuable references and could serve as solid foundations for subsequent research. Dispersants would have environmental benefits in subsequent spill accidents with the reduction of environmental damage from the spilled oil. Comprehensive and systematic studies of ecological impacts for dispersants can accelerate their opportunity for applications in marine oil spill responses. To achieve this objective, the following perspectives 


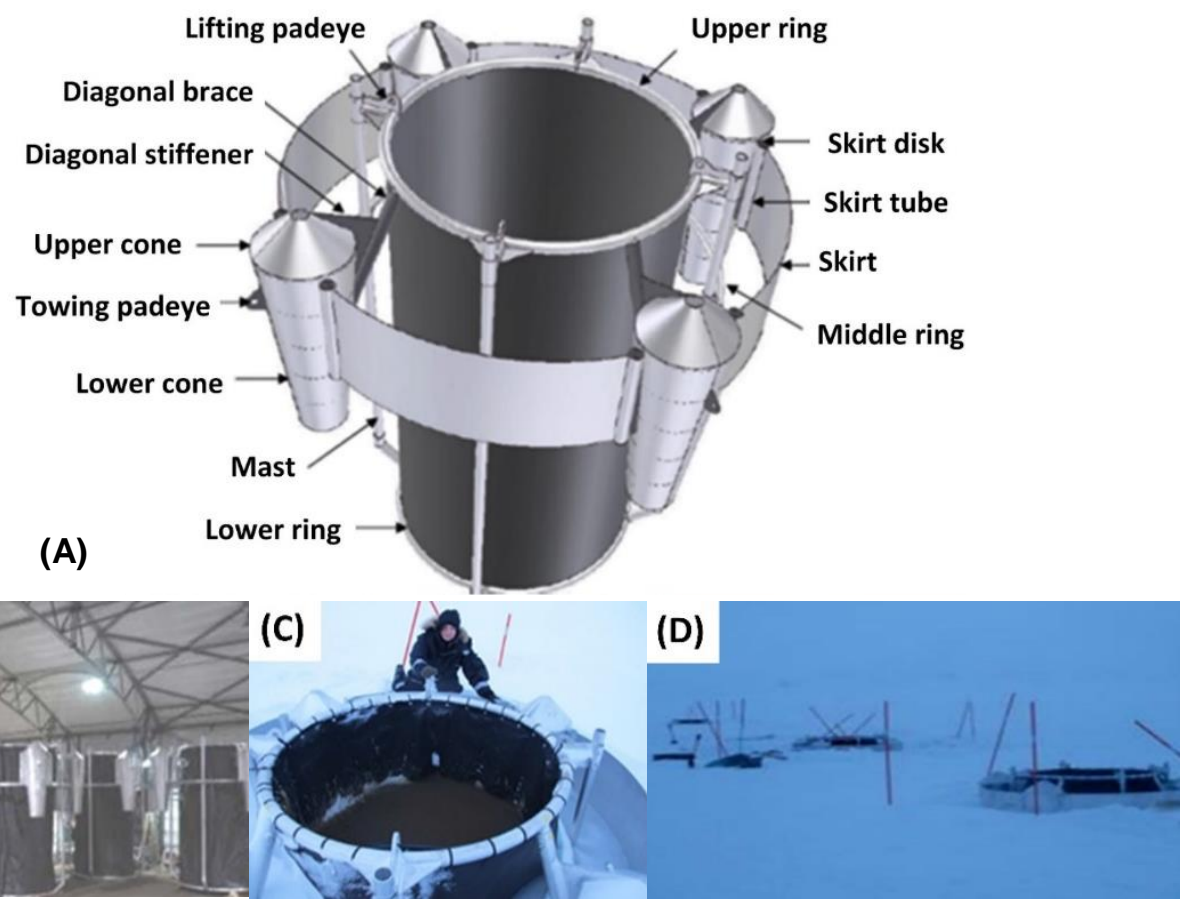

Note: The diagram of a mesocosm with its vertical skirt surrounded by its 4 floats (A). The mesocosms in the warehouse before deployment (B) and set in the ice (C and D).

Figure 11. Mesocosms deployed in Arctic to assess conduct oil spill impact assessment in ice on the microbial community (Camus and Smit, 2019).

can be considered in future research:

Developments of the comprehensive database: The development of a comprehensive database provides decision-makers, stockholders, and researchers a guideline to quickly evaluate the ecological impacts in the planning stage for spill responses. Baseline environmental, ecological and biological data/resources of dispersants and dispersed oil in a specific region would be beneficial to support timely, informed response decisions. Additionally, a well-built database has a great potential for further modeling developments and evaluation procedures. A series of modules for the prediction of efficiency and impacts could be proposed, which increase the capacities of current oil spill trajectory and weathering models and decision support systems.

Improvements of toxicity tests: How to shorten the testing period and decrease the impacts to exposure animals is a challenging in toxicity tests. With the improvements in computation capacities, artificial intelligence approaches (i.e., deep learning or machine learning) could be a possible means to reduce the reliance on large sample sizes of tests. In addition, more field-based ecological studies to improve the understanding of the ecological relevance and significant of dispersed-oil exposure under real world conditions are desired.

Productions of eco-friendly dispersants: New dispersants (e.g., biodispersants) are multifunctional products generated from microorganisms and other sources to further enhance the bioavailability of hydrophobic immiscible and mostly inaccessible substrates, and affect the associated ecological toxicity in a positive way. More efforts are needed to identify more producers, improve the productivity and decrease the production cost, and evauate the associated dispersion effectivenessand ecological impacts comprehensively.

Understanding in harsh environments: Harsh environments (e.g., low temperature and ice coverage) make the traditional response devices and tools less effective, including the use of dispersants. Countermeasures and application guidelines designated for cold regions (e.g., the Arctic) are needed. Better understanding of ecological toxicity and impacts of dispersants and dispersed oil in harsh environments could improve response operations suitable for cold climates. The environmental risk and ecological impact analysis of dispersant applications should be also considered into decision-making processes and overall response tools in these regions and include the presence of ice.

Acknowledgment. This work was supported by Fisheries and Oceans Canada (DFO) under the Multi-Partner Research Initiative (MPRI) program.

\section{References}

Aurand, D. and Coelho, G. (2005). Cooperative aquatic toxicity testing of dispersed oil and the "chemical response to oil spills: Ecological Effects Research Forum (CROSERF)" a model for cooperative research by industry and government. Ecosystem Management and Associates, Inc., Technical Report 07-03, 125.

Aurand, D., Pond, R., Coelho, G., Cunningham, M., Cocanaur, A., and 
Stevens, L. (2005). The use of consensus ecological risk assessments to evaluate oil spill response options: lessons learned from workshops in nine different locations. International Oil Spill Conference Proceedings, 2005(1): 379-386. https://doi.org/10.7901/ 2169-3358-2005-1-379

Baca, B., Rosch, E., DeMicco, E.D., and Schuler, P.A. (2014). TROPICS: 30-year Follow-up and Analysis of Mangroves, Invertebrates, and Hydrocarbons. International Oil Spill Conference Proceedings, 2014(1), 1734-1748. https://doi.org/10.7901/2169-3358-2014.1.1734

Baca, B., Ward, G.A., Lane, C.H., and Schuler, P.A. (2005). Net environmental benefit analysis (NEBA) of dispersed oil on nearshore tropical ecosystems derived from the 20 year "TROPICS" field study. International Oil Spill Conference Proceedings, 2005(1), 453-456. https://doi.org/10.7901/2169-3358-2005-1-453

Bagby, S.C., Reddy, C.M., Aeppli, C., Fisher, G.B., and Valentine, D.L. (2017). Persistence and biodegradation of oil at the ocean floor following Deepwater Horizon. Proc. of the National Academy of Sciences, the United States of America, 114(1), E9-E18. https://doi. org/10.1073/pnas. 1610110114

Ballou, T.G., Dodge, R., Hess, S., and Knap, A. (1989). Tropical oil pollution investigations in coastal systems (tropics): the effects of untreated and chemically dispersed Prudhoe Bay crude oil on mangroves, seagrasses, and corals in Panama. Oil dispersants: new ecological approaches: ASTM International, 229-256. https://doi. org/10.1520/STP1 8665S

Bejarano, A. (2014). Dtox: A worldwide quantitative database of the toxicity of dispersants and chemically dispersed oil. Final report submitted to the NOAA Coastal Response Research Center (CRRC). Research Planning, Inc., 36.

Bejarano, A.C. (2018). Critical review and analysis of aquatic toxicity data on oil spill dispersants. Environmental Toxicology and Chemistry, 37(12), 2989-3001. https://doi. org/10.1002/etc.4254

Bejarano, A.C. (2019). Further development and refinement of interspecies correlation estimation models for current-use dispersants. Environmental Toxicology and Chemistry, 38(8), 1682-1691. https: //doi.org/10.1002/etc. 4254

Bejarano, A.C. and Barron, M.G. (2014). Development and practical application of petroleum and dispersant interspecies correla tion models for aquatic species. Environmental Science and Technology, 48(8), 4564-4572. https://doi.org/10.1021/es500649v

Bejarano, A.C., Farr, J.K., Jenne, P., Chu, V., and Hielscher, A. (2016). The Chemical Aquatic Fate and Effects database (CAFE), a tool that supports assessments of chemical spills in aquatic environments. Environmental Toxicology and Chemistry, 35(6), 1576-1586. https: //doi.org/10.1002/ etc.3289

Board, O.S., National Academies of Sciences, Engineering, and Medicine. (2020). The use of dispersants in marine oil spill response. National Academies Press. https://doi.org/ 10.17226/25161

Cailleaud, K., Bassères, A., Gelber, C., Postma, J.F., Ter Schure, A.T., Leonards, P.E., Redman, A.D., Whale, G.F., Spence, M.J., and Hjort, M. (2019). Investigating predictive tools for refinery effluent hazard assessment using stream mesocosms. Environmental Toxicology and Chemistry, 38(3), 650-659. https://doi.org/10.1002/etc. 4338

Camus, L. and Smit, M.G. (2019). Environmental effects of Arctic oil spills and spill response technologies, introduction to a 5 year joint industry effort. Marine Environmental Research, 144, 250-254. https://doi.org/10.1016/j.mar envres.2017.12.008

Cedre. (2011). DISCOBIOL Project. https://crrc.unh.edu/sites/crrc.un h.edu/files/media/docs/Workshops/dwg/discobiol.news.2011.pdf

Chen, B., Ye, X., Zhang, B., Jing, L., and Lee, K. (2019). Marine oil spills-Preparedness and countermeasures. World Seas: An Environmental Evaluation, 407-426. https://doi.org/10.1016/B978-012-805052-1.00025-5

Clark, J.R., Bragin, G.E., Febbo, E.J., and Letinski, D.J. (2001). Toxicity of physically and chemically dispersed oils under continuous and environmentally realistic exposure conditions: Applicability to dispersant use decisions in spill response planning. International Oil Spill Conference Proceedings. https://doi.org/10.7901/2169-33582001-2-1249

Coffinet, S., Cossu-Leguille, C., Bassères, A., Gonnet, J.F., and Vasseur, P. (2008). Response of the bivalve Unio tumidus and freshwater communities in artificial streams for hazard assessment of methyl methacrylate. Environmental Toxicology and Chemistry: An International Journal, 27(6), 1371-1382. https://doi.org/10.1897/ 06-506.1

Curd, H. (2011). The use of dispersant for the control of volatile organic compounds. International Oil Spill Conference Proceedings. https://doi.org/10.7901/2169-3358-2011-1-359

DeMicco, E., Schuler, P.A., Omer, T., and Baca, B. (2011). Net Environmental Benefit Analysis (NEBA) of Dispersed Oil on Nearshore Tropical Ecosystems: Tropics-the 25th Year Research Visit. International Oil Spill Conference Proceedings, 2011(1), abs282. https://doi.org/10. 7901/2169-3358-2011-1-282

Desmarquest, J., Croquette, J., Merlin, F., Bocard, C., and Gatellier, C. (1983). A field test and assessment of oil dispersant efficiency. International Oil Spill Conference Proceedings, 1983 (1), 574. https: //doi.org/10.7901/2169-3358-1983-1-574

Doerffer, J.W. (2013). Oil spill response in the marine environment. Elsevier. https://doi.org/10.1016/B978-0-08-041000-5.50012-4

Dussauze, M., Marguerie, J., Auffret, M., Merlin, F.X., and Le Floch, S. (2011). Discobiol program: investigation of dispersant use in coastal and estuarine. International Oil Spill Conference Proceedings, 2011(1), abs 173. https://doi. org/10.7901/2169-3358-2011-1-173

European Maritime Safety Agency (EMSA). (2016). Overview of national dispersant testing and approval policies in the EU. http:// www.emsa.europa.eu/about/items.html?cid=2\&I d=2671

Fan, F., Zhang, B., Liu, J., Cai, Q., Lin, W., and Chen, B. (2020). Towards sulfide removal and sulfate reducing bacteria inhibition: Function of biosurfactants produced by indigenous isolated nitrate reducing bacteria. Chemosphere, 238, 124655. https://doi.org/10. 1016/j.chemosphere.2019. 124655

Fingas, M.F. (2005). A Survey of Tank Facilities for Testing Oil Spill Dispersants. Prince William Sound Regional Citizens' Advisory Council, pp 21-25.

Floch, F.M.S.L. (2012). Mémoire scientifique. Etude ANR-07-ECOT004-01 ADEME: 0794C005. Cedre report, R.12.12.b.C/3258.

Floch, S.L. (2002). The ievoli sun shipwreck: styrene toxicity and olfactorythreshold in marine organisms. Paper presented at the Seafer Seas Seminar; Technical lessons learnt from the Erika incident and other oil spills - Brest, March 13-16, 2002.

French-McCay, D.P. (2002). Development and application of an oil toxicity and exposure model, OilToxEx. Environmental Toxicology and Chemistry, 21(10), 2080-2094. https://doi.org/10.1002/etc.562 0211011

Garcia-Blanco, S., Moteleb, M., Suidan, M.T., Venosa, A.D., Lee, K., and King, D.W. (2001). Restoration of an oil-contaminated St. Lawrence River shoreline: bioremediation and phytoremediation. Proc. of the 2001 International Oil Spill Conference: Global strategies for prevention, preparedness, response, and restoration, March 26-29, 2001.

Goodarzi, F. and Zendehboudi, S. (2019). A comprehensive review on emulsions and emulsion stability in chemical and energy industries. The Canadian Journal of Chemical Engineering, 97(1), 281-309. https://doi.org/10.1002/ cjce.23336

Grote, M., van Bernem, C., Böhme, B., Callies, U., Calvez, I., Christie, B., Colcomb, K., Damian, H.P., Farke, H., Gräbsch, C., Hunt, A., Höfer, T., Knaack, J., Kraus, U., Le Floch, S., Le Lann, G., Leuchs, H., Nagel, A., Nies, H., Nordhausen, W., Rauterberg, J., Reichenbach, D., Scheiffarth, G., Schwichtenberg, F., Theobald, N., Voß, J., and Wahrendorf, D.S. (2018). The potential for dispersant use as a maritime oil spill response measure in German waters. Marine 
Pollution Bulletin, 129(2), 623-632. https:// doi.org/10.1016/j.mar polbul.2017.10.050

Harrison, J.A. (2020). "Down Here We Rely on Fishing and Oil": Work Identity and Fishers' Responses to the BP Oil Spill Disaster. Sociological Perspectives, 63(2), 333-350. https://doi.org/10.1177 /0731121419881140

Hermens, J.L.M. (1989). Quantitative structure-activity relationships of environmental pollutants, Reactions and Processes, The Handbook of Environmental Chemistry, vol 2 / 2E. Springer, Berlin, Heidelberg. pp 111-162. https://doi.org/10.1007/978-3-540-461616_3

JIP, A.O.S.R.T. (2017). Long term ice exposure studies for enhancing arctic neba science base. International Oil Spill Conference Proceedings, 2017(1), 1128-1145. https://doi. org/10.7901/2169-33582017.1.1128

Kirby, T. (1996). Sea Empress Environmental Evaluation CommitteeInitial Report-July 1996. Spill Science and Technology Bulletin 3(3), 103-106. https://doi.org/10.1016/ S1353-2561(96)00020-5

Kitchen, R., Bonner, J., Autenrieth, R., Donnelly, K., and Ernest, A.N. (1997). Introducing COSS: A new and unique oil spill research facility. Canada

Lagadec, P. (2009). A new cosmology of risks and crises: time for a radical shift in paradigm and practice. Working Papers, 26(4), 473 486. https://hal.archives-ouvertes.fr/hal-00370652

Lee, K., Nedwed, T., Prince, R.C., and Palandro, D. (2013). Lab tests on the biodegradation of chemically dispersed oil should consider the rapid dilution that occurs at sea. Marine Pollution Bulletin, 73(1), 314-318. https://doi.org/10.1016/ j.marpolbul.2013.06.005

Lee, K., Venosa, A.D., Haines, J.R., Suidan, M.T., Merlin, F.X., and V. Jarry. (2000). Recovery of an Experimentally Oiled Freshwater Wetland. Environment Canada Arctic and Marine Oil Spill Program Technical Seminar (AMOP).

Li, P., Chen, B., Li, Z., and Jing, L. (2016). ASOC: A novel agentbased simulation-optimization coupling approach-algorithm and application in offshore oil spill responses. Journal of Environmental Informatics, 28(2), 90-100. https://doi.org/10.3808/jei.201600354

Liu, N., Paranjape, R., Hara, E., and Asghari, K. (2015). Statistical parameter estimation to find oil pipeline leakage using a fiber optic sensor. Journal of Environmental Informatics, 5(1), 1-8. https://doi. org/10.3808/jei.200500040

Liu, Z. and Callies, U. (2020). A probabilistic model of decision making regarding the use of chemical dispersants to combat oil spills in the German Bight. Water Research, 169, 115196.1-115196.14. https:// doi.org/10.1016/j.watres. 2019.115196

McCay, D.F. and Graham, E. (2014). Quantifying tradeoffs-net environmental benefits of dispersant use. International Oil Spill Conference Proceedings, 2014(1), 762-775. https://doi.org/10.7901/ 2169-3358-2014.1.762

Mearns, A.J., Venosa, A.D., Lee, K., and Salazar, M. (1997). Fieldtesting bioremediation treating agents: lessons from an experimental shoreline oil spill. Proc. of the 1997 International Oil Spill Conference, April 7-10, 1997.

Merlin, F.X., Le Floch, S., Dussauze, M., Quentel, C., Theron, M., and Thomas, H. (2011). Discobiol Program: investigation of dispersant use in coastal and Estuarine waters. Arct. Mar. Oil Spill Program Tech. Seminar, 2, 126.

National Academies of Sciences, Engineering, and Medicine. (2020). The Use of Dispersants in Marine Oil Spill Response. Washington, DC: The National Academies Press. https://doi.org/10.17226/25161

National Oceanic and Atmospheric Administration (NOAA, E). (2015). Chemical Aquatic Fate and Effects (CAFE) Database: Version. https://response.restoration.noaa.gov/ cafe

Page, C., Fuller, C., Autenrieth, R.L., Bonner, J.S., Louchouarn, P., Tissot, P., and McDonald, T. (2001). Shoreline cleaner use in a sandy beach environment. International Oil Spill Conference, pp.
1485-1488.

Passow, U. and Ziervogel, K. (2016). Marine snow sedimented oil released during the Deepwater Horizon spill. Oceanography, 29(3), 118-125. https://doi.org/10.2307/ 24862714

Pfetzing, E. and Cuddeback, J. (1993). Use of chemical dispersants for marine oil spills. United States, pp 1-136.

Prince, R.C. (2015). Oil spill dispersants: boon or bane? Environmental Science and Technology, 49(11), 6376-6384. https://doi.org/ 10.1021/acs.est.5b00961

Redman, A.D., Butler, J.D., Letinski, D.J., and Parkerton, T.F. (2017). Investigating the role of dissolved and droplet oil in aquatic toxicity using dispersed and passive dosing systems. Environmental Toxicology and Chemistry, 36(4), 1020-1028. https://doi.org/10.1002/etc. 3624

Redman, A.D., McGrath, J.A., Stubblefield, W.A., Maki, A.W., and Di Toro, D.M. (2012a). Quantifying the concentration of crude oil microdroplets in oil-water preparations. Environmental Toxicology and Chemistry, 31(8), 1814-1822. https://doi.org/10.1002/etc.1882

Redman, A.D. and Parkerton, T.F. (2015). Guidance for improving comparability and relevance of oil toxicity tests. Marine Pollution Bulletin, 98(1-2), 156-170. https://doi.org/10.1016/j.marpolbul.201 5.06.053

Redman, A.D., Parkerton, T.F., McGrath, J.A., and Di Toro, D.M. (2012b). PETROTOX: An aquatic toxicity model for petroleum substances. Environmental Toxicology and Chemistry, 31(11), 2498 -2506. https://doi.org/10.1002/etc. 1982

Renegar, D.A., Schuler, P, and Turner, N. (2017). Coral toxicity research for determining thresholds for dispersantuse-neba calculations. International Oil Spill Conference Proceedings, 2017(1). https://doi.org/10.7901/ 2169-3358-2017.1.1267

Saadoun, I.M. (2015). Impact of oil spills on marine life. Emerging pollutants in the environment-current and further implications. Marcelo L. Larramendy and Sonia Soloneski, IntechOpen, pp 75104. https://doi.org/10.5772/60455

Shubbar, R., Lee, D., Gzar, H., and Rood, A. (2019). Modeling air dispersion of pollutants emitted from the daura oil refinery, BaghdadIraq using the CALPUFF modeling system. Journal of Environmental Informatics Letters, 2(1), 28-39. https://doi.org/10.3808/jeil. 201900014

Wan, Z. and Chen, J. (2018). Human errors are behind most oil-tanker spills. Nature, 560, 161-163. https://doi.org/10. 1038/d41586-01805852-0

Wise, J. and Wise, J.P. (2011). A review of the toxicity of chemical dispersants. Reviews on Environmental Health, 26(4), 281-300. https://doi.org/ 10.1515/REVEH.2011.035

Word, J.Q. (2013). Environmental impacts of arctic oil spills and arctic spill response technologies. Final report for the Arctic Oil Spill Response Technology-Joint Industry Programme, pp 205.

Xue, J., Yu, Y., Bai, Y., Wang, L., and Wu, Y. (2015). Marine oildegrading microorganisms and biodegradation process of petroleum hydrocarbon in marine environments: a review. Current Microbiology, 71(2), 220-228. https://doi. org/10.1007/s00284-015-0825-7

Ye, X., Chen, B., Lee, K., Storesund, R., and Zhang, B. (2020). An integrated offshore oil spill response decision making approach by human factor analysis and fuzzy preference evaluation. Environmental Pollution, 262, 114294. https://doi.org/10.1016/j.envpol. 2020.114294

Zhang, B., Matchinski, E.J., Chen, B., Ye, X., Jing, L., and Lee, K. (2019). Marine oil spills-Oil pollution, sources and effects. World Seas: An Environmental Evaluation. Elsevier, pp. 391-406. https: //doi.org/10.1016/B978-0-12-805052-1.00024-3

Zhu, Z., Zhang, B., Cai, Q., Ling, J., Lee, K., and Chen, B. (2020). Fish waste based lipopeptide production and the potential application as a bio-dispersant for oil spill control. Frontiers in Bioengineering and Biotechnology, 8, 734. https://doi.org/10.3389/fbioe.2020.00734 